\title{
A Brief Performance Test of the M06 Family of Density Functionals for the Prediction of the Maximum Absorption Wavelength of Thioindigo in Several Solvents
}

\author{
Francisco Cervantes-Navarro and Daniel Glossman-Mitnik*
}

Nanocosmos Virtual Laboratory, Centro de Investigación en Materiales Avanzados, Miguel de Cervantes 120, Complejo Industrial Chihuahua, Chihuahua, Chih. 31109, México. daniel.glossman@cimav.edu.mx, Tel.: +52 6144391151.

Received January 31, 2012; accepted February 6, 2013

\begin{abstract}
The Minnesota family of density functionals (M06, M06L, M06-2X and M06-HF) has been used to calculate the UV-Vis spectra of the thioindigo molecule in solvents of different polarities using time-dependent density functional theory (TD-DFT) and the polarized continuum model (PCM). The maximum absorbance wavelengths predicted for each functional were compared with the known experimental results.

Key words: Thioindigo, TD-DFT, PCM, UV-Vis, M06 Density Functionals.
\end{abstract}

\section{Introduction}

Natural organic dyes have long been used to color textiles and polymer substrates. These colored materials greatly influence our emotions and aesthetic perceptions. Traditionally, organic dyes have been used to color materials, especially textiles, via dyeing technology. In more recent times, however, organic colorants have become increasingly important in high-technology fields, such as electronic materials, devices, and reprographics. These organic materials are called functional dyes [1].

Indigo is a dye with a long history. Its importance has been retained in part because of the global popularity of blue denim. Until the commercialization of its chemical synthesis at the end of the 19th century, indigo was extracted from plants [2]. Thioindigo, in which an N-H group is replaced by S, is one of the many derivatives synthesized since the commercialization of indigo.

In density functional theory (DFT) [3], the functionals that depend on the kinetic energy density are called meta-GGAs and lead to hybrid meta-GGAs with the inclusion of some exact exchange. These functionals are the most modern and have allowed the calculation of binding energies with chemical precision comparable to that of experimental results. Among the hybrid meta-GGAs there are functionals that have been developed by Truhlar et al at the University of Minnesota, which are known as M05, M05-2X, M06, M06L, M06-2X and M06HF [4-6]. For M06-HF, the average deviation is approximately $50 \mathrm{~nm}$ for borondipyrromethene dyes [7], and this functional works well for open-chain cyanine for small molecules [8] and has been applied to predict a wide range of properties [9-12]. Apart from the local functional M06L, the other functionals are hybrid meta-GGAs with different percentages of exact exchange that have been developed by adjusting predictions to the experimental values of some properties. However, as these
Resumen. Los funcionales de la densidad de la familia Minnesota (M06, M06L, M06-2X y M06-HF) han sido considerados para calcular el espectro UV-Vis, de la molécula tioíndigo en solventes de diferentes polaridades, usando la teoría de funcionales de la densidad dependiente del tiempo (TD-DFT) y el modelo del continuo polarizado (PCM). Las longitudes de onda de máxima absorción, predicha para cada funcional fueron comparadas con resultados experimentales conocidos.

Palabras clave: Tioíndigo, TD-DFT, PCM, UV-Vis, Funcionales de densidad M06.

functionals are approximations of an unknown energy density functional, determining the best functional for a given system and predicting its properties requires calculations to be performed for similar systems and properties and then compared with the experimental results to verify concordance.

The thioindigo molecule provides an opportunity to study the predictive performance of a density functional because the experimental UV-Vis spectra of thioindigo in different solvents are well known. The aim of this letter is to assess the performance of the M06 family of density functionals for the prediction of the maximum absorbance wavelength of thioindigo in different solvents. This research will allow us to understand not only which functional is better at describing this particular property in this particular system but also any behaviors of the density functionals that may depend on the solvent dipole moment.

\section{Computational Details}

All computations were performed using the Gaussian 09 [15] series of programs with the density functional methods as implemented in the computational package. The equilibrium geometries of the molecule were determined via the gradient technique. The force constants and vibrational frequencies were determined by computing the analytical frequencies at the stationary points obtained after optimization to confirm that they were true minima. The basis sets used in this work were 6-311G $(\mathrm{d}, \mathrm{p})$ and $6-311+\mathrm{G}(2 \mathrm{~d}, \mathrm{p})$ [16] (for further information, see references 17-19).

To calculate the molecular structure and properties of the studied system, we chose the hybrid meta-GGA density functionals M06, M06L, M06-2X and M06-HF [4-6], which consistently provide satisfactory results for several relevant structural 
and thermodynamic properties. The solvation energies were computed using the integral equation formalism - polarized continuum model (IEF-PCM) [20], including the UAKS definition of radii, with dimethylformamide, ethanol, tetrachloroethane, chloroform, xylene, toluene, benzene, carbon tetrachloride and cyclohexane as solvents.

The calculation of the ultraviolet-visible (UV-Vis) spectra of the studied systems was performed by solving the timedependent DFT (TD-DFT) equations according to the method implemented in Gaussian 09 [15, 21-23]. The equations were solved for 20 excitations.

The infrared (IR) and UV-Vis spectra were calculated and visualized using the Swizard program [24, 25]. In all cases, the displayed spectra provided the calculated frequencies and absorption wavelengths that allowed us to predict the maximum absorption wavelength of the studied system.

\section{Results and Discussion}

The optimized structure of the thioindigo molecule was calculated using the four M06 density functionals in nine solvents of different polarity: dimethylformamide or $\operatorname{DMF}(\varepsilon=37.2)$, ethanol $(\varepsilon=24.8)$, tetrachloroethane or TCE $(\varepsilon=8.2)$, chloroform ( $\varepsilon$ $=4.7)$, xylene $(\varepsilon=2.27)$, toluene $(\varepsilon=2.37)$, benzene $(\varepsilon=2.27)$, carbon tetrachloride or $\mathrm{CCl}_{4}(\varepsilon=2.23)$, and cyclohexane $(\varepsilon=$ 2.02). In each case, the true minima were confirmed following an inspection of the frequencies and the IR spectra obtained after the frequency calculation.

Based on the optimized ground-state molecular structures, we calculated the absorption spectra in each case using a protocol consisting of the following three steps:

1. The vertical excitation at the ground-state equilibrium is calculated using TD-DFT with the IEF-PCM solvation model, which corresponds to a linear response in non-equilibrium solvation.

2. The ground-state energy is calculated using the IE-PCM solvation model to prepare the system for state-specific non-equilibrium solvation by saving the solvent reaction field from the ground state.

3. The non-equilibrium solvation energy from the ground state is read, and the first excited-state energy is computed using a state-specific method and a self-consistent IEF-PCM calculation to compute the energy in the solution by making the electrostatic potential of the solute self-consistent with the reaction field.

The results of the calculations are presented in Table 1, which shows the maximum absorption wavelength (in $\mathrm{nm}$ ) for the thioindigo molecule in solvents of decreasing polarity and for each of the density functionals considered. The experimental values have been taken from the data collected in the literature [13], also including the strongest oscillator strength. Additionally, the principal orbital involved in the transition is displayed.
The results in Table 1 clearly indicate that for all solvents, the performance of the M06 functional is impressive. For solvents with high dipole moments, such as ethanol and DMF, the M06 functional outperforms the other functionals, including PBE0 [14]. None of the functionals with high HF exchange content are accurate enough, and each functional underestimates the experimental results.

In comparison with results in [13], M06 and PBE0 offer maximum errors of 11 and $6 \mathrm{~nm}$, respectively, for solvents with high dipole moments. PBE0 and M06 have similar accuracies for solvents with low dipole moments.

For the system under study, the M06 functional family with strong Hartree-Fock exchange (M06-2X and M06-HF) overestimated the energies; on the other hand, M06-L, which only includes local exchange, underestimated the energies. M06, with $27 \%$ exact exchange, overestimated energy slightly for solvents with low dipole moments, for which the orbital transition involved in the strongest oscillator strength is $\mathrm{H}-3->\mathrm{L}+0$. For solvents with high dipole moments, M06 predicted $\lambda$ max with exceptional accuracy for ethanol and DMF, for which the orbital transition involved in the strongest oscillator strength is $\mathrm{H}-2->\mathrm{L}+0$.

Based on the calculated MAE, the best functional for solvated thioindigo is PBE0, followed closely by M06. However, PBE0 has a higher computational cost than M06.

\section{Conclusions}

The M06 family of density functionals has been assessed for its performance in predicting the maximum absorption wavelength of thioindigo in nine solvents of varying polarity. The results indicate that the M06 functional can reproduce the experimental values with impressive accuracy for solvents with high dipole moments, such as DMF and ethanol, and perform well for intermediate values of the orbital overlap parameter [26]. The inclusion of increased HF exchange, such as in the M06-2X and M06-HF functionals, leads to inaccurate, underestimated values.

Although PBE0 is the most accurate functional in terms of its MSE, we propose M06 for thioindigo solvated with high dipole moments because it is computationally cheaper.

The orbital transition involved in the strongest oscillator strength is $\mathrm{H}-2->\mathrm{L}+0$. DMF and ethanol have the strongest oscillator strength (approximately 0.3 ) and may be useful for the practical application of quantum chemistry in the design of functional dyes.

The results of this work indicate that functionals can contribute to the study of the UV-Vis absorbance and possibly other molecular properties of related thioindigoid molecules.

\section{Acknowledgments}

This work has been partially supported by Consejo Nacional de Ciencia y Tecnología (CONACYT, Mexico). FCN gratefully acknowledges a fellowship from CONACYT. DGM is a researcher with CONACYT and CIMAV. 
Table 1. Maximum absorption wavelength of the thioindigo molecule (in $\mathrm{nm}$ ) calculated using the M06 density functionals in several solvents and the strongest oscillator strength and principal orbital involved in the transition.

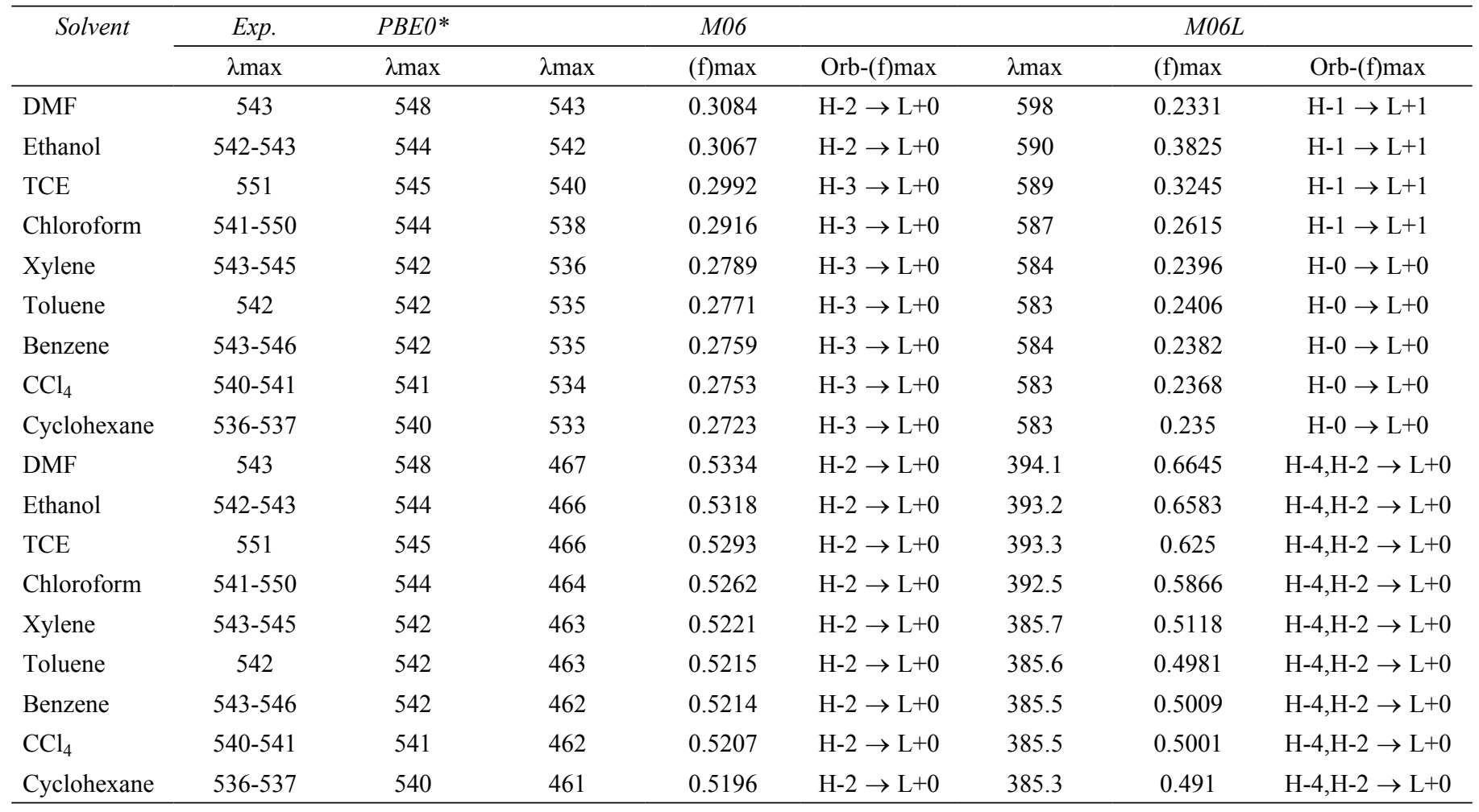

* [13].

Table 2. Mean absolute errors (MAE) for each functional.

\begin{tabular}{cc}
\hline Functional & MAE \\
\hline PBE0* $^{*}$ & 0.78 \\
M06 & 4.94 \\
M06L & 44.24 \\
M06-2X & 78.53 \\
M06-HF & 153.37 \\
\hline
\end{tabular}

*MAE calculated with Ref-13 data.

\section{References}

1. Kim, S.H. (ed.), Functional Dyes, Elsevier B.V., Oxford, UK. 2006.

2. Bechtold, T.; Mussak, R. (eds.), Handbook of Natural Colorants, John Wiley \& Sons, Chichester, UK. 2009.

3. Parr, R.G.; Yang, W. Density Functional Theory of Atoms and Molecules, Oxford University Press, New York, 1989.

4. Zhao, Y.; Truhlar, D.G. Acc. of Chem. Res. 2008, 41(2), 157.

5. Zhao, Y.; Truhlar, D.G. Theor. Chem. Acc. 2008, 120, 215.

6. Zhao, Y.; Truhlar, D.G. Chem. Phys. Lett. 2011, 502, 1.

7. Nithya, R.; Kolandaivel, P.; Senthilkumar, K. Mol. Phys. 2012, $110,8,445$.

8. Jacquemin, D.; Zhao, Y.; Valero R.; Adamo C.; Ciofini I.; Truhlar D. G. J. Chem. Theo. Comput. 2012, 8, 1255.

9. Valero, R.; Costa, Y.; Moreira, I.; Truhlar, D. G.; Illas, F. J. Chem. Phys. 2008, 128, 114103.

10. Tarnopolsky, A.; Karton, A.; Sertchook, R.; Vuzman, D.; Martin, J. M. L. J. Phys. Chem. A 2008, 112, 3-8.
11. Jacquemin, D.; Perpete, E. A.; Ciofini I.; Adamo C.; Valero, R.; Zhao, Y.; Truhlar D. G. J. Chem. Theo. Comput. 2010, 6, 20712085.

12. Jacquemin, D.; Zhao, Y.; Valero R.; Adamo C.; Ciofini I.; Truhlar D. G. Proc. Nat. Acad. Sci. 2009, 106, 4963-4968.

13. Jacquemin, D.; Preat, J.; Wathelet, V.; Fontaine, M.; Perpete, E. J. Am. Chem. Soc. 2006, 128, 2072.

14. Jacquemin, D.; Preat, J.; Wathelet, V.; Perpete, E. J. Mol. Struct. (Theochem) 2005, 731, 67-72.

15. Gaussian 09, Revision A.1, Frisch, M. J.; Trucks, G. W.; Schlegel, H. B.; Scuseria, G. E.; Robb, M. A.; Cheeseman, J. R.; Scalmani, G.; Barone, V.; Mennucci, B.; Petersson, G. A.; Nakatsuji, H.; Caricato, M.; Li, X.; Hratchian, H. P.; Izmaylov, A. F.; Bloino, J.; Zheng, G.; Sonnenberg, J. L.; Hada, M.; Ehara, M.; Toyota, K.; Fukuda, R.; Hasegawa, J.; Ishida, M.; Nakajima, T.; Honda, Y.; Kitao, O.; Nakai, H.; Vreven, T.; Montgomery, Jr., J. A.; Peralta, J. E.; Ogliaro, F.; Bearpark, M.; Heyd, J. J.; Brothers, E.; Kudin, K. N.; Staroverov, V. N.; Kobayashi, R.; Normand, J.; Raghavachari, K.; Rendell, A.; Burant, J. C.; Iyengar, S. S.; Tomasi, J.; Cossi, M.; Rega, N.; Millam, N. J.; Klene, M.; Knox, J. E.; Cross, J. B.; Bakken, V.; Adamo, C.; Jaramillo, J.; Gomperts, R.; Stratmann, R. E.; Yazyev, O.; Austin, A. J.; Cammi, R.; Pomelli, C.; Ochterski, J. W.; Martin, R. L.; Morokuma, K.; Zakrzewski, V. G.; Voth, G. A.; Salvador, P.; Dannenberg, J. J.; Dapprich, S.; Daniels, A. D.; Farkas, Ö.; Foresman, J. B.; Ortiz, J. V.; Cioslowski, J.; Fox, D. J. Gaussian, Inc., Wallingford CT, 2009.

16. Lewars, E. Computational Chemistry - Introduction to the Theory and Applications of Molecular and Quantum Mechanics, Kluwer Academic Publishers, Dordrecht, 2003.

17. Young, D.C. Computational Chemistry - A Practical Guide for Applying Techniques to Real-World Problems, John Wiley \& Sons, New York, 2011.

18. Jensen, F. Introduction to Computational Chemistry, 2nd edn., John Wiley \& Sons, Chichester, England, 2007. 
19. Cramer, C.J. Computational Chemistry - Theories and Models, 2nd edn., John Wiley \& Sons, Chichester, England, 2004.

20. Tomasi, J.; Mennucci, B.; Cances, E. J. Mol. Struct. (Theochem) 1999, 464, 211.

21. Stratmann, R.E.; Scuseria, G.E.; Frisch, M.J. J. Chem. Phys. 1998 , $109,8218$.

22. Bauernschmitt, R.; Ahlrichs, R. Chem. Phys. Lett. 1996, 256, 454.
23. Casida, M.E.; Jamorski, C.; Casida, K.C.; Salahub, D.R. J. Chem. Phys. 1998, 108 (11), 4439.

24. Gorelsky, S. Swizard program Revision 4.6, http://www.sg-chem. net/

25. Gorelsky, S.; Lever, A. J. Organomet. Chem. 2001, 635 (1-2), 187.

26. Dev, P.; Agrawal, S.; English N. J. J. Chem. Phys. 2012, 136, 224301 